\title{
Removal of Lead from Aqueous Medium Using Xanthate Modified Apple Juice Residue
}

\author{
Deepak Bashyal, Puspa Lal Homagai ${ }^{*}$ and Kedar Nath Ghimire \\ Central Department of Chemistry, Tribhuvan University, Kirtipur, Kathmandu, Nepal \\ e-mail: homagaipl@gmail.com
}

\begin{abstract}
This study investigated the feasibility of chemically modified apple juice residue as a novel type of adsorbent for lead removal from aqueous medium. FTIR studies were carried out to understand the type of functional groups in unmodified and modified apple juice residue responsible for metal binding process. Equilibrium adsorption data were fitted in terms of monolayer adsorption at $\mathrm{pH} 4$ by batch method. The kinetics was studied for biosorption processes and data were described by pseudo second order model. The equilibrium constant and Gibbs free energy of the adsorption at $25^{\circ} \mathrm{C}$ were determined. The mechanism of sorption was found to obey the ion exchange and complexation method.
\end{abstract}

Keywords: Heavy metal, biosorption, xanthate, ion exchange, complexation

\section{Introduction}

The presence of heavy metals in the environment has become a great concern due to their increasing discharge, toxic nature and other adverse effects into the receiving water bodies and thereby affecting significantly the quality of water supply. Metals are considered as toxic pollutants and non biodegradable in nature which undergo transformations and have great environmental, public health and economic impacts. ${ }^{1}$ Lead is one of the toxic environmental pollutants which is found in nature and also found as introduced contaminant into the environment. Its presence even at trace levels can pose health hazards ${ }^{2}$. Acute lead poisoning usually affects gastrointestinal tract, nervous system, liver and kidney, reproductive system, brain, and sometimes even causes death. Chronic exposure to lead is associated with sterility, abortion, stillbirths, and neonatal deaths. ${ }^{3,4}$ Many physicochemical methods including sorption to metal oxide, clay, activated carbon, organic sorbents have been extensively used to remove toxic metals, in recent years an alternative technology called bio-sorption by the usage of biomass, fiber, peat, living plants and bacteria as adsorbents is in progress. Biosorbents are cheap materials often with high affinity and binding capacity for metals and are readily available in most places.

Among the adsorbents used to remove heavy metals, those containing sulfur-bearing groups have a high affinity for heavy metals but a low affinity for light metals. From the

"Corresponding author 
different sulphur bearing compounds, xanthates are found most prominent because they are easy to prepare with relatively inexpensive reagents, highly insoluble and have high stability constant values of the metal complexes formed according to HSAB classification system. Xanthates are formed by reacting on organic hydroxyl-containing substrate with carbon disulfide under caustic condition. ${ }^{5,6}$ The basic chemical reaction is shown below. ${ }^{7}$

$$
\mathrm{R}-\mathrm{OH}+\mathrm{S}=\mathrm{C}=\mathrm{S}+\mathrm{NaOH} \longrightarrow \mathrm{R}-\mathrm{OC} \stackrel{\mathrm{SNa}}{\mathrm{S}}+\mathrm{H}_{2} \mathrm{O}
$$

Apple juice residue is mostly composed of cellulose, hemicellulose, pectin, lignin, chlorophyll pigments and other low molecular weight hydro-carbons. ${ }^{8}$ Many of these contain several hydroxyl functional groups, which make the apple juice residue a potential substrate for the synthesis of xanthates. In the present work, we attempted to prepare novel xanthated material for adsorption of lead. The fractional attainment to the equilibrium, the mechanism of sorption, the equilibrium rate constant, the order of the reaction and hence the standard Gibbs-free energy for the reaction at $25{ }^{\circ} \mathrm{C}$ were established.

\section{Experimental Methods}

Apple juice residue obtained from local market was first washed thoroughly with distilled water to remove soluble material and dried in an oven at $50^{\circ} \mathrm{C}$ for $50 \mathrm{~h}$. The dried apple residue was crushed and sieved into different fractions. Approximately $40 \mathrm{gm}$ of apple residue was treated with $250 \mathrm{ml}$ of $17 \% \mathrm{NaOH}$ solution for $2 \mathrm{~h}$ to remove chlorophyll pigment and low molecular weight compounds. Then $10 \mathrm{ml}$ of $\mathrm{CS}_{2}$ was added and mixture was stirred in rotary shaker for $24 \mathrm{~h}$. The obtained products were washed several times with distilled water. After drying in an oven at $30^{\circ} \mathrm{C}$ overnight, the dried solid was stored in desiccators at room temperature. The prepared xanthate adsorbent was abbreviated as MAJR (modified apple juice residue) hereafter for convenience.

To determine the maximum amount of active sites on modified adsorbent, $30 \mathrm{mg}$ of dried $\mathrm{H}^{+}$-form gel and $30 \mathrm{~mL}$ of $0.01 \mathrm{M}$ of $\mathrm{NaOH}$ solution were equilibrated for $24 \mathrm{~h} .{ }^{9}$ Finally the acid-base titration was employed for supernatant solution ${ }^{10}$. Fourier transform infrared (FTIR) analysis was performed to identify functional groups on apple juice residue (AJR) and chemically modified apple juice residue (MAJR). FTIR spectra were obtained using a spectroscope (JASCO FT/IR, Japan) at resolution $1 \mathrm{~cm}^{-1}$. Pressed potassium bromide $(\mathrm{KBr})$ pellets at a sample/ $\mathrm{KBr}$ weight ratio of 1:100 were scanned and recorded between 4000 and $400 \mathrm{~cm}^{-1}$.

The adsorption of $\mathrm{Pb}^{+2}$ was investigated in batch equilibrium experiments. The experiments were carried out in $125 \mathrm{~mL}$ conical flasks containing $20 \mathrm{~mL}$ of metal ion solutions of different concentrations and $20 \mathrm{mg}$ of the adsorbents, shaken for $24 \mathrm{~h}$ at 100 $\mathrm{rpm}$ in a mechanical shaker. A series of adsorption experiments were conducted at different initial $\mathrm{pH}$ to study adsorption mechanism. After the desired shaking period for each batch, the concentration of $\mathrm{Pb}^{2+}$ ion was measured using atomic absorption spectrophotometer (AAS; Perkin Elmer AA-100). 
The amount of metal adsorbed was calculated using the following equation:

$$
\mathrm{q}=\left(\mathrm{C}_{\mathrm{i}}-\mathrm{C}\right) \mathrm{V} / \mathrm{m}
$$

where, $\mathrm{C}_{\mathrm{i}}$-initial concentration of metal ion $\mathrm{mmol} / \mathrm{L} ; \mathrm{C}$-Concentration of metal ion after certain period of time $\mathrm{mmol} / \mathrm{L} ; \mathrm{m}$-mass of adsorbent $\mathrm{g}$; $\mathrm{V}$ - the volume of the solutions $\mathrm{mL}$.

\section{Results and discussion}

\section{Characterization of adsorbent}

The broad and intense absorption peaks at around $3403 \mathrm{~cm}^{-1}$ from FTIR spectrum shown in Fig. 1, corresponds to the $\mathrm{O}-\mathrm{H}$ stretching vibration due to inter and intramolecular hydrogen bonding of polymeric compounds such as phenols, alcohols, and carboxylic acids, as in cellulose, pectin and lignin, thus showing the presence of free hydroxyl groups on the adsorbent surface. Similarly, peak at $2930 \mathrm{~cm}^{-1}$ corresponding to C$\mathrm{H}$ stretching, $1749 \mathrm{~cm}^{-1}$ to stretching vibration of bond due to non ionic carboxylic groups: $-\mathrm{COOH}$ and $-\mathrm{COOCH}_{3}$. The peaks at 1652 and $1448 \mathrm{~cm}^{-1}$ are due to asymmetric and symmetric stretching vibration of $\mathrm{C}=\mathrm{O}$ in ionic carboxylic groups (-COO-), respectively. Aliphatic acid group vibration at $1259 \mathrm{~cm}^{-1}$ may be assigned to deformation vibration of $\mathrm{C}$ $=\mathrm{O}$ and stretching formation of $-\mathrm{OH}$ of carboxylic acids and phenols. ${ }^{11}$ Peaks at $1078 \mathrm{~cm}^{-1}$ may be due to stretching vibration of $\mathrm{C}-\mathrm{OH}$ of alcoholic groups and carboxylic acids. ${ }^{5}$ Due to the chemical modification some distinct changes are noted in the spectrum of MAJR. The broad peak at $3403 \mathrm{~cm}^{-1}$ in the AJR shifts to $3398 \mathrm{~cm}^{-1}$ in the MAJR which indicates that the hydroxyl groups have combined with $\mathrm{CS}_{2}$. The major adsorption characteristic bands of xanthate groups lie in the region $800-1225 \mathrm{~cm}^{-1}$. The presence of sulfur groups in the MAJR has been identified by the appearance of new peaks at 538, 1050 and $1165 \mathrm{~cm}^{-1}$ corresponding to $\mathrm{C}-\mathrm{S}, \mathrm{C}=\mathrm{S}$ and $\mathrm{S}-\mathrm{C}-\mathrm{S}$ symmetric stretching. ${ }^{12}$

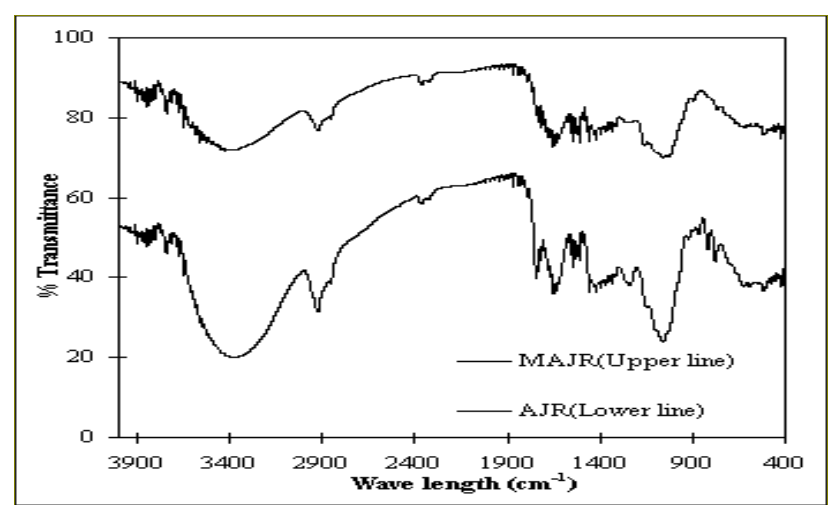

Figure 1: FTIR analysis result on the surface of AJR and MAJR

The maximum amount of active sites on modified sample was found as $2.52 \mathrm{~mol} / \mathrm{kg}$. It revealed that the prepared adsorbent would possess higher amount of ion exchangeable sites for metal cation. 


\section{Adsorption equilibrium}

To investigate the optimal $\mathrm{pH}$ for maximum adsorption of $\mathrm{Pb}^{+2}$ ions the experiment was examined over a $\mathrm{pH}$ range 3.5 to 4.5 by using initial $\mathrm{Pb}^{+2}$ concentration of 0.024 $\mathrm{mmol} / \mathrm{L}$ to $2.41 \mathrm{mmol} / \mathrm{L}$. The effect of initial concentration on efficiency of MAJR to remove $\mathrm{Pb}^{+2}$ at different $\mathrm{pH}$ is depicted in Fig. 2. The maximum adsorption of $\mathrm{Pb}^{+2}$ was obtained at $\mathrm{pH} 4$.

The effect of $\mathrm{pH}$ can be explained considering the surface charge on the adsorbent material. At low $\mathrm{pH}$, adsorption of $\mathrm{Pb}^{2+}$ ions was intensively decreased towards a fixed number of adsorption sites due to high positive charge density of protons on the surface sites. This is a result of competition between $\mathrm{Pb}^{2+}$ ions and $\mathrm{H}_{3} \mathrm{O}^{+}$for binding sites. ${ }^{13}$ With increasing $\mathrm{pH}$, electrostatic repulsion decreases due to reduction of positive charge density on the sorption sites thus resulting in an enhancement of metal adsorption to get optimum value. Above this, the adsorption of $\mathrm{Pb}^{2+}$ was decreased with increasing $\mathrm{pH}$, owing to the interaction between $\mathrm{OH}^{-}$and $\mathrm{Pb}^{2+}$ ions followed by solvation and hydrolysis in the solution. The process involved is as follows. ${ }^{7}$

$$
\begin{aligned}
& \mathrm{Pb}^{+2}+\mathrm{nH}_{2} \mathrm{O}-\cdots \\
& \mathrm{Pb}\left(\mathrm{H}_{2} \mathrm{O}\right)_{\mathrm{n}}^{2+} \longrightarrow \mathrm{Pb}\left(\mathrm{H}_{2} \mathrm{O}\right)_{\mathrm{n}}^{2+} \\
& \mathrm{nPb}^{2+}+\mathrm{mH}_{2} \mathrm{O} \rightarrow \mathrm{Pb}\left(\mathrm{H}_{2} \mathrm{O}\right)^{\mathrm{n}-1}+\mathrm{H}^{+}
\end{aligned}
$$

The $\mathrm{pH}$ speciation shows that the dominant species is $\mathrm{Pb}(\mathrm{OH})_{2}$ at $\mathrm{PH}>5$ and $\mathrm{Pb}^{2+}$ and $\mathrm{Pb}(\mathrm{OH})^{+}$at $\mathrm{pH}<5$. If $\mathrm{pH}$ of the media controlled carefully during experiment, the adsorption characteristics of $\mathrm{Pb}^{2+}$ onto MAJR were investigated by fitting data obtained for the degree of surface coverage into different adsorption isotherms which corresponds to the relationship between the mass of the solute adsorbed per unit mass of the adsorbent $\mathrm{q}_{\mathrm{e}}$ and the solute concentration for the solution at equilibrium $\mathrm{C}_{\mathrm{e}}$.

The sorption data was tested against Langmuir and Freundlich adsorption isotherm models. The linear form of the Langmuir model as shown below was used ${ }^{14}$.

$$
\mathrm{C}_{\mathrm{e}} / \mathrm{q}_{\mathrm{e}_{-}}=1 / \mathrm{bq}_{\mathrm{m}}+\mathrm{C}_{\mathrm{e}} / \mathrm{q}_{\mathrm{m}}
$$

Linear plots of $\mathrm{C}_{\mathrm{e}} / \mathrm{q}_{\mathrm{e}}$ vs $\mathrm{C}_{\mathrm{e}}$ (Fig. 3) were employed to determine the value of $\mathrm{q}_{\max }$ $(\mathrm{mmol} / \mathrm{g})$ and $\mathrm{b}(\mathrm{L} / \mathrm{mmol})$ and are the ultimate adsorption capacity and relative energy(binding constant) of adsorption respectively. Linearity of the plots indicated the applicability of the adsorption isotherm. The parameters of the Langmuir isotherm for each heavy metal estimated from Fig. 2 at $\mathrm{pH} 3.5,4$ and 4.5 are shown in Table 1 by assuming that only monolayer adsorption took place by MAJR and the maximum $\mathrm{Pb}^{+2}$ uptake values obtained was $1.22 \mathrm{mmol} / \mathrm{g}$ at $\mathrm{pH} 4$.

The essential characteristics and the feasibility of the Langmuir isotherm in terms of a dimensionless constant, separation factor or equilibrium parameter $R_{L}$, which is defined as ${ }^{11}$.

$$
\mathrm{R}_{\mathrm{L}}=1 /\left(1+\mathrm{bC}_{\mathrm{i}}\right)
$$

The $R_{L}$ value indicates the shape of the isotherm as $R_{L}>1$ : unfavourable, $R_{L}=1$ : linear, $0<\mathrm{R}_{\mathrm{L}}>1$ : favourable, $\mathrm{R}_{\mathrm{L}}=0$ : irreversible adsorption. 


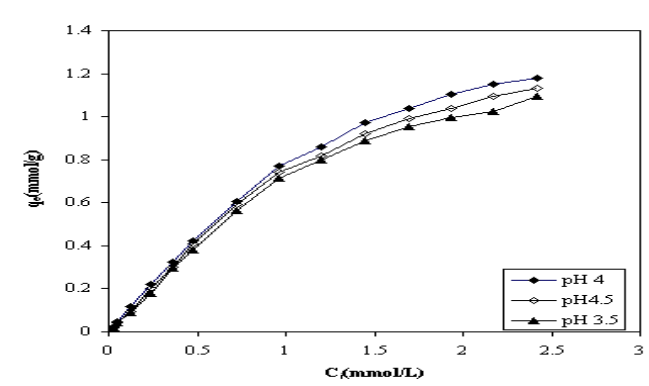

Figure 2: Effect of initial concentration for adsorption of $\mathrm{Pb}^{2+}$ at different $\mathrm{pH}$ values

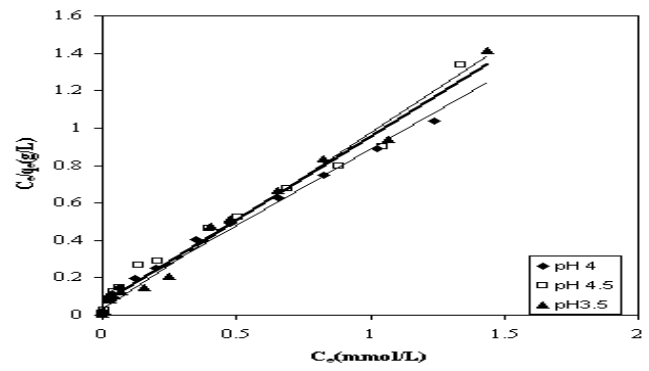

Figure 3: Langmuir adsorption isotherms for $\mathrm{Pb}^{2+}$ adsorption at different $\mathrm{pH}$ values

The adsorption data obtained were then fitted to the Freundlich adsorption isotherm which is the earliest relationship known describing the adsorption equilibrium and is expressed by the following equation ${ }^{15}$.

$$
\log \mathrm{q}_{\mathrm{e}}=\log \mathrm{K}+1 / \mathrm{n} \log \mathrm{C}_{\mathrm{e}}
$$

The Freundlich isotherm constants $\mathrm{K}$ and $\mathrm{n}$ are constants incorporating all factors affecting the adsorption process such as of adsorption capacity and intensity of adsorption. The constants $\mathrm{K}$ and $\mathrm{n}$ were calculated from equation 4 and Freundlich plots as shown in Fig. 4 are depicted in Table 1 . The values of $n$ between 1 and 10 (i.e. $1 / n$ less than 1 ) represent a favorable adsorption ${ }^{16}$. The $\mathrm{n}$ values obtained for adsorbent considered for study represent a beneficial adsorption
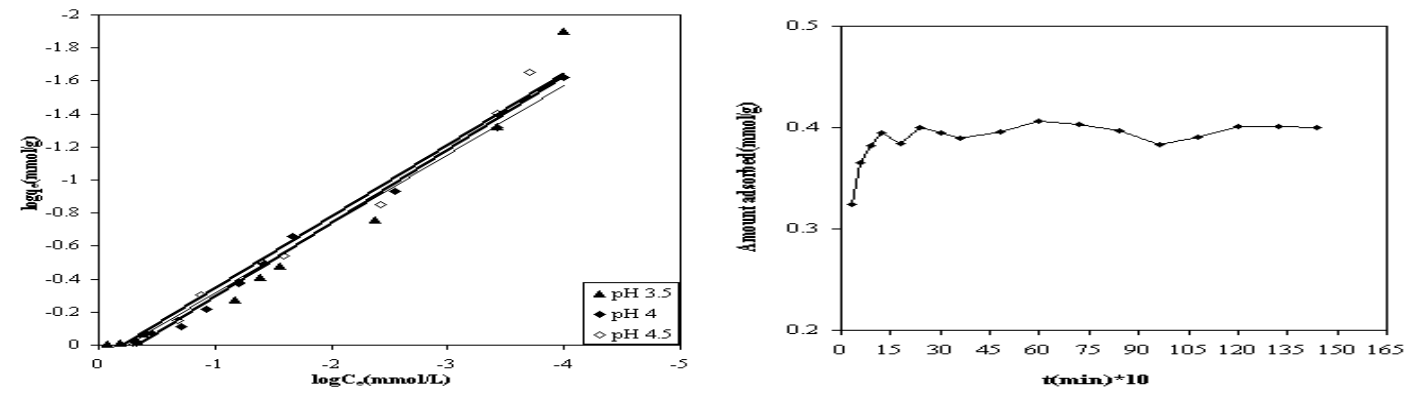

Figure 4: Freundlich plot for the adsorption Figure 5: Effect of contact time for adsorption of $\mathrm{Pb}^{+2}$ at different $\mathrm{pH}$ values of $\mathrm{Pb}^{+2}$ by MAJR

From the Table 2 the data obtained represent a favorable adsorption for the concentration range studied. The equilibrium constant of adsorption of $\mathrm{Pb}^{2+}$ onto MAJR is related to the free energy of adsorption as follows ${ }^{17}$ :

$$
\Delta \mathrm{G}=-\mathrm{RT} \ln \mathrm{K}
$$

where $\Delta \mathrm{G}$ is the Gibbs free energy change $(\mathrm{KJ} / \mathrm{mol}), \mathrm{R}$ is the ideal gas constant $(8.314 / \mathrm{mol} \mathrm{k}), \mathrm{T}$ is the solution temperature (Kelvin), and $\mathrm{K}$ is the thermodynamic equilibrium. The values of $\Delta \mathrm{G}$ for adsorption of $\mathrm{Pb}^{+2}$ at $\mathrm{pH} 3.5,4$ and 4.5 were $33.20,35.31$ and $33.53 \mathrm{KJ} / \mathrm{mol}$, respectively. The negative value for Gibbs free energy shows that the adsorption process of $\mathrm{Pb}^{2+}$ on alkali-treated apple juice residue is spontaneous in nature. 
Table 1: Adjustable parameters for the isotherms models for $\mathrm{Pb}^{+2}$ adsorption by MAJR at different $p H$ values

\begin{tabular}{|c|c|c|c|c|c|c|c|}
\hline \multicolumn{4}{|c|}{ Langmuir constants } & \multicolumn{3}{|c|}{ Freundlich constants } & \multirow[b]{2}{*}{$\begin{array}{c}\text { Gibb's free } \\
\text { energy change } \\
\Delta \mathrm{G}(\mathrm{kJ} / \mathrm{mol})\end{array}$} \\
\hline $\mathrm{pH}$ & $\begin{array}{l}\mathrm{q}_{\max } \\
(\mathrm{mmol} / \\
\mathrm{g})\end{array}$ & $\begin{array}{l}\text { B } \\
(\mathrm{L} / \mathrm{mmol})\end{array}$ & $\begin{array}{l}\text { Correlation } \\
\text { coefficient }\end{array}$ & $\mathrm{K}(\mathrm{mmol} / \mathrm{g})$ & $\mathrm{n}$ & $\begin{array}{l}\text { Correlation } \\
\text { coefficient }\end{array}$ & \\
\hline $\mathrm{pH} 3.5$ & 1.06 & 11.91 & 0.9903 & 1.39 & 2.2 & 0.9366 & 33.20 \\
\hline $\mathrm{pH} 4.0$ & 1.22 & 27.91 & 0.9987 & 1.26 & 2.4 & 0.9881 & 35.31 \\
\hline $\mathrm{pH} 4.5$ & 1.12 & 13.61 & 0.9912 & 1.22 & 2.3 & 0.9811 & 33.53 \\
\hline
\end{tabular}

Table 2: Separation factor or equilibrium parameter $R_{L}$ for adsorption of $\mathrm{Pb}(I I)$ at $\mathrm{pH} 4$.

\begin{tabular}{|c|c|c|}
\hline $\begin{array}{l}\text { Initial concentration } \\
\mathrm{Ci}(5 \mathrm{mmol} / \mathrm{L}) \mathrm{Pb}(\mathrm{II})\end{array}$ & $\begin{array}{l}\text { Initial concentration } \\
\mathrm{Ci}(200 \mathrm{mmol} / \mathrm{L}) \mathrm{Pb}(\mathrm{II})\end{array}$ & $\begin{array}{l}\text { Initial concentration } \\
\mathrm{C}_{\mathrm{i}}(500 \mathrm{mmol} / \mathrm{L}) \mathrm{Pb}(\mathrm{II})\end{array}$ \\
\hline 0.598 & 0.036 & 0.014 \\
\hline
\end{tabular}

The study of adsorption dynamics describes the solute uptake rate and evidently these rate controls the residence time of adsorbate uptake at the solid-solution interface so essential for a successful application of the adsorption process in wastewater treatment. It was observed from Fig. 3 that the amount of $\mathrm{Pb}^{2+}$ adsorption increased with contact time and occurred in two stages i.e. initial rapid uptake within 15-20 min followed by subsequent slow uptake, until steady state condition was attained.

The rate kinetics of $\mathrm{Pb}^{2+}$ adsorption onto MAJR was analyzed by using Lagergren and pseudo-second order model. The conformity between experimental data and the model predicted values was expressed by correlation coefficient. follows ${ }^{8}$.

The intergral form of Lagergren (pseudo first order) model generally expressed as

$$
\log \left(\mathrm{q}_{\mathrm{e}}-\mathrm{q}_{\mathrm{t}}\right)=\log \mathrm{q}_{\mathrm{e}}-\mathrm{k}_{1} \mathrm{t} / 2.303
$$

The kinetics of adsorption process may also be described using pseudo-second-order rate equation. This assumes that the rate is proportional to the square of the number of remaining free surface sites. The linearized form of equation is expressed as ${ }^{13}$;

$$
\mathrm{t} / \mathrm{q}_{\mathrm{t}}=1 / \mathrm{k}_{2} \mathrm{q}_{\mathrm{e}}^{2}+\mathrm{t} / \mathrm{q}_{\mathrm{e}}
$$

The applicability of the Lagergren and pseudo-second order models were examined by each linear plot of $\log \left(\mathrm{q}_{\mathrm{e}}-\mathrm{q}_{\mathrm{t}}\right)$ vs. $\mathrm{t},\left(\mathrm{t} / \mathrm{q}_{\mathrm{t}}\right) \mathrm{vs}$. $t$, respectively and are presented in Figs 6 and 7 , respectively. The values of rate constants and correlation coefficients for each model are shown in Table 3. Obviously, the adsorption process could be well described by the pseudosecond order equation, indicating the process mechanism to be chemical adsorption being the rate controlling step with the formation of monolayer coverage on the adsorbent surface. ${ }^{13}$ 


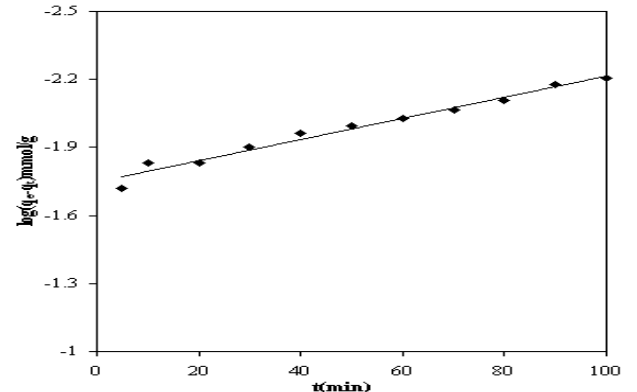

Figure 6: Lagergren plot for adsorption of $\mathrm{Pb}^{+2}$ by $\mathrm{MAJR}$

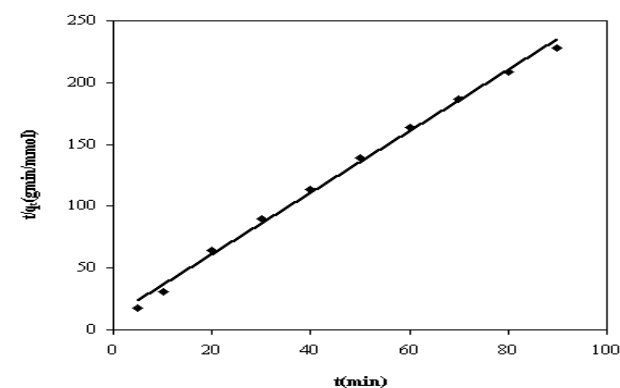

Figure 7: Pseudo-second order plot for adsorption of $\mathrm{Pb}^{+2}$ by $M A J R$

Table 3: Rate kinetics for adsorption of $\mathrm{Pb}^{2+}$ with comparison of calculated and experimental $q_{e}$ values.

\begin{tabular}{|l|l|l|c|c|l|c|}
\hline \multirow{2}{*}{$\begin{array}{l}\mathrm{q}_{\mathrm{e}} \text { expt } \\
\mathrm{mmol} / \mathrm{g}\end{array}$} & \multicolumn{4}{|c|}{ Lagergren } & \multicolumn{3}{c|}{ Pseudo second-order } \\
\cline { 2 - 7 } & $\mathrm{k}_{1} 1 / \mathrm{min}$ & $\begin{array}{l}\mathrm{q}_{\mathrm{e}} \text { cal, } \\
\mathrm{mmol} / \mathrm{g}\end{array}$ & $\begin{array}{c}\text { Correlation } \\
\text { coefficient }\left(\mathrm{R}^{2}\right)\end{array}$ & $\begin{array}{c}\mathrm{k}_{2} \\
\mathrm{~g} / \mathrm{mmol} . \mathrm{min}\end{array}$ & $\begin{array}{l}\mathrm{q}_{\mathrm{e}} \\
\mathrm{mmol} / \mathrm{g}\end{array}$ & $\begin{array}{c}\text { Correlation } \\
\text { coefficient }\left(\mathrm{R}^{2}\right)\end{array}$ \\
\hline 0.420 & 0.010 & 0.011 & 0.976 & 0.556 & 0.402 & 0.999 \\
\hline
\end{tabular}

\section{Mechanism of adsorption}

The identification of xanthate functional groups from FTIR on the surface MAJR provides the better understanding of adsorption mechanism. From the affirmation between maximum amount of exchanged protons on adsorbent and amount of metal uptake, the adsorption of $\mathrm{Pb}^{2+}$ ion on the surface may be regarded as ion- exchange as well as some complexation and or chelation. By ion exchange, two negative charged sulfur atoms of MAJR participate in capturing one divalent metal ion. However, complex formation occurs between four sulfur atoms and one divalent metal ion (Scheme 1). It is postulated that metal ion adsorption process could undergo both ion exchange and complex formation. ${ }^{8,13}$ Because lead belong to transition metals, which have empty orbitals that can be occupied by electrons to form complex and considering steric hindrance, mechanism (b) is the most possible adsorption process. 7,18

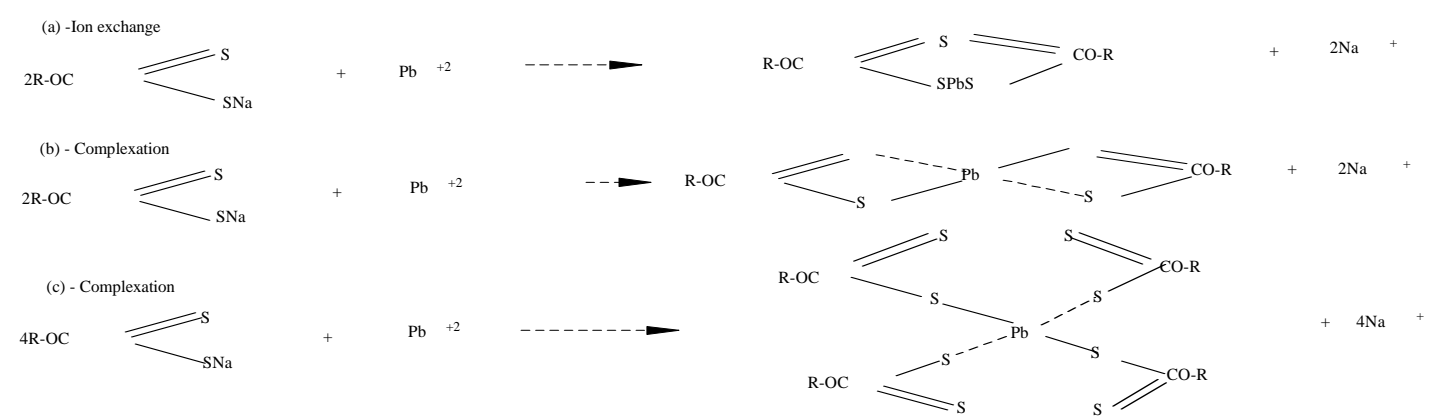

Scheme 1: Plausible adsorption mechanisms for adsorption of $\mathrm{Pb}^{+2}$ ions onto MAJR 
In addition, during the adsorption process equilibrium $\mathrm{pH}$ values were increased if no buffer solution was added into the experimental solutions. This phenomenon can be explained by proposing that $\mathrm{Na}^{+}$ions were released into the solutions according to both ion exchange and complexation mechanisms they then combined with $\mathrm{OH}^{-}$ions to form alkali which strengthened the alkalinity of the solutions.

\section{Conclusions}

This work indicated that adsorbent devised by incorporation of xanthate group onto the surface of apple juice residue could be used as viable bio-sorbent for the treatment of $\mathrm{Pb}^{2+}$ ions bearing wastewater streams. The maximum amount of exchangeable sites possessing in novel adsorbent is $2.52 \mathrm{~mol} / \mathrm{kg}$. The maximum amount of $\mathrm{Pb}^{2+}$ ions uptakes was found $1.22 \mathrm{mmol}$ per unit gm of adsorbent at $\mathrm{pH} 4$. The adsorption data pertaining for adsorption process is thermodynamically feasible and good agreement with Langmuir isotherm and pseudo second-order kinetic model. During the adsorption, predominant ionexchange mechanism is supposed to be involving between metal ion and cation containing with sulphur at xanthate group and proved by FTIR spectrum. The quantity of exchanged proton was highly relative to the concentration of metal adsorbed. From the superior result on $\mathrm{Pb}^{2+}$, it might be helpful for removing other toxic heavy metals like cadmium, zinc, cupper, nickel and mercury containing wastewater.

\section{References}

1. A. Greenberg, "Standard Method for the Estimation of Water and Waste water, $16^{\text {th }}$ ed., APHA; AWWA; WPCF, 1985.

2. G. Naja and B. Volesky, Environ. Sci. Technol., 2006, 40, 3962

3. R.T. Daher, Anal Chem., 1995, 67, 405.

4. N. R. Warner, J. Levy, K. Harpp, F. Farruggia, Hydrogeo. J., 2008, 16, 321

5. A. S. Dine, A. Aboulayt, M. Bensitel , J.C. Lavalley, J. Mol. Cat., 2000, 16, 125

6. P. L. Homagai, K. N. Ghimire, K. Inoue, Biores.Technol.2010, 110, 2067

7. S. Liang, X. Guo, N. Feng, Q. Tian, J. Hazzard. Matter., 2009, 170, 425

8. B. Y. Zhao, T. Hirose, K. A. HU, D. Zhang, J. Mater. Sci. Lett., 2002, 21, 333

9. K. N. Ghimire, K. Inoue, K. Ohto, T. Hayasida, Biores. Technol., 2008, 99, 32

10. H. P. Boehm, Carbon 1994, 32, 759

11. Z. Reddad, C. Gerente, Y. Andres, Env. Sci. Technol., 2002, 36, 2067

12. L. H.Little, G.W.Poling, J. Leja, Can. J. Chem., 1961, 39, 783

13. P. Lodeiro, H. Herrero, J. Hazard. Matter., 2006 B137, 244

14. I. Langmuir, J. Am. Chem. Soc., 1918, 40, 1361

15. Y. Liu, S. F. Yang and H. Xu, Biochem., 2003, 38,997

16. A. A. Abia, J. C. Igwe, African J. Biotechnol., 2005, 6, 509

17. S. Milonjic, J. Serb. Chem. Soc., 2007, 72(12), 1363

18. Y. S. Ho, G. Mckay, D. J. Wase, C. F. Foster, Adsorpt. Sci. Tech., 2000, 18, 639

19. K. N. Ghimire, K. Inoue, K. Ohto, Sep. Sci. Technol., 2007, 42, 2003 